\title{
Etiological diagnosis of reproductive tract infections by laboratory tests in women presenting with different syndromes
}

\author{
Surabhi Saharan ${ }^{1}$, Jaya Choudhary ${ }^{2 *}$, Aakarsh Sinha ${ }^{3}$
}

${ }^{1}$ Senior Resident, Department of Obstetrics and Gynaecology, PDU Medical College, Churu-331001, Rajasthan, INDIA. 2Professor, Department of Obstetrics and Gynaecology, Mahatma Gandhi Medical College and University, Jaipur, Rajasthan, INDIA. ${ }^{3}$ Senior Resident, Department Of Obstetrics And Gynaecology, Madhubani Medical College Andhospital, Madhubani, Bihar, INDIA. Email: spiffingsurbhi@gmail.com

Abstract Background: Reproductive tract infections (RTIs) pose as a threat of major health problem around the world. They are more common in developing countries like in India. In etiological approach diagnosis of RTIs done by identification of etiological agents by various laboratory tests. Aim: To employ etiological approaches for the diagnosis of reproductive tract infections. Material and Methods: In this prospective study 300 patients with reproductive tract infections patients who were included. Diagnosis of RTIs was done by various laboratory tests such as vaginal $\mathrm{pH}$, Whiff test, wet Mount, Gram staining, vaginal swab cultural and sensitivity, pap smear and serological tests. Results: Out of 300 cases, 147 (49\%) cases were normal, bacterial vaginosis was diagnosed in $21 \%$ cases, candidiasis in $20.33 \%, 6.67 \%$ cases had mixed infection and 3\% were of Trichomonas. Whiff test was positive in $83(27.67 \%)$ cases. Most of the cases $210(70 \%)$ were observed normal on vaginal swab culture. Candida species were present in $27 \%$ cases while Trichomoniasis were present in 3\% cases. Conclusion: The treatment may be initiated on the basis of signs and symptoms, however, it is essential that the treatment is modified as and when laboratory test results become available.

Key Words: Reproductive tract infections, etiological diagnosis, vaginal culture, serological tests

*Address for Correspondence:

Dr Jaya Choudhary, Professor, Department of Obstetrics and Gynaecology, Mahatma Gandhi Medical College and University, Jaipur, Rajasthan, INDIA.

Email: spiffingsurbhi@gmail.com

Received Date: 20/04/2020 Revised Date: 12/06/2020 Accepted Date: 27/07/2020

DOI: https://doi.org/10.26611/10121537

This work is licensed under a Creative Commons Attribution-NonCommercial 4.0 International License. (oc)) EY-NC

\begin{tabular}{|l|l|}
\hline \multicolumn{2}{|c|}{ Access this article online } \\
\hline Quick Response Code: & Website: \\
\hline & www.medpulse.in \\
\hline
\end{tabular}

\section{INTRODUCTION}

Reproductive tract infections (RTIs) pose as a threat of major health problem around the world. ${ }^{1}$ They are more common in developing countries like in India. ${ }^{2}$ These infections cause suffering and distress for both women and men around the world., ${ }^{3,4}$ These account for the second most important cause for morbidity and mortality in women of reproductive age due to the lack of medical facilities available. In etiological approach diagnosis of RTIs done by identification of etiological agents by various laboratory tests such as vaginal $\mathrm{pH}$, Whiff test, wet Mount, Gram staining, vaginal swab cultural and sensitivity, pap smear and serological tests for HIV, syphillis, hepatitis and also for other reproductive tract infections. In contrast to this, syndromic diagnosis is done by signs and symptoms, where there are advanced laboratory facilities are not available. The purpose of this study was to employ etiological approaches for the diagnosis of reproductive tract infections.

\section{MATERIAL AND METHODS}

In this prospective study 300 patients with reproductive tract infections patients who were included for the selection criteria. The study was conducted at Department 
of Obstetrics and Gynecology of a tertiary care teaching hospital over a period of two years. Institutional Ethical Committee permission was taken prior to the commencement of the study. Informed consent was taken from all the included patients.

\section{Inclusion criteria}

- Women of reproductive age group (20-45 years)

- Women presenting with various symptoms and signs of RTIs such as vaginal discharge, pain in lower abdomen and genital ulcer.

\section{Exclusion criteria}

- Unmarried women.

- Women with pregnancy and any uterine pathology.

- Patient with bleeding per vagina.

- Diagnosed genital malignancy.

- Patient not given valid consent.

Methodology

Detailed history including menstrual, obstetric and sexual history of the patients were taken and general, physical and local examination was done and clinical symptoms and sign were noted. All reproductive tract infection patients were subjected for clinical examination based on symptoms and sign and use the flow chart describe by WHO. On per speculum examination, vaginal culture from posterior fornix was taken with sterile swab stick and send for culture and sensitivity. $\mathrm{P}^{\mathrm{H}}$ of vaginal discharge noted by $\mathrm{P}^{\mathrm{H}}$ strips dipped in vaginal discharge, change in color was noted. Discharge collected on the posterior blade of speculum was taken on the different glass slides for the preparation of different tests (wet mount, $\mathrm{KOH}$ mountwhiff test, Gram's staining) and pap's smear taken with help of ayre's spatula. The odour of the discharge was noted and also did whiff test (bacterial vaginosis), and types of color and nature of discharge also noted. Wet smear examination was done for Trichomonas vaginalis, mycelium and yeast cells, presence of clue cells. Serological tests such as HBsAg, VDRL and HIV were done. Internal examination (per vaginal) was done to find out the size, shape of uterus and rule out the tenderness and masses in the fornix and all patients underwent USG to rule out the pelvic pathology.

\section{RESULTS}

A total of 300 women fulfilling the criteria were included in the study. Of these 300 women, majority of the women $145(48.33 \%)$ were in the age group $31-40$ years while $43 \%$ in age group $20-30$ years and $8.67 \%$ in age group $>40$ years. the mean age of the study group was $31.52 \pm 6.085$ years. With regard to their education, $31.7 \%$ were educated till secondary, $20 \%$ were having primary education, $15.3 \%$ were illiterate and higher education holder were $17.7 \%$. Out of 300 women, 285 (95\%) were married, while $4 \%$ had divorcee and only $1 \%$ were widow. The present study showed that the rural women were more suffered than urban $(60 \%$ vs $40 \%)$. Maximum number of patients 99 (33\%) were para 2 and $30.33 \%$ patients were multiparous women (>P3), $68(22.67 \%)$ patients were primipara women while $14 \%$ patients had no children (nulliparous) (Table 1).

Table 1: Characteristics of the studied cases

\begin{tabular}{ccc} 
Characteristics & No. of patients & Percentage (\%) \\
\hline Age in years & & \\
20 to 30 & 129 & $43.00 \%$ \\
31 to 40 & 145 & $48.33 \%$ \\
$>40$ & 26 & $8.67 \%$ \\
Locality & & \\
Rural & 180 & $60 \%$ \\
Urban & 120 & $40 \%$ \\
Marital status & & \\
Married & 285 & $95 \%$ \\
Divorcee & 12 & $4 \%$ \\
Widow & 03 & $1 \%$ \\
Parity & & \\
Nulliparity & 42 & $14 \%$ \\
Primi & 68 & $22.7 \%$ \\
Para 2 & 99 & $33 \%$ \\
Multiparity & 91 & $30.3 \%$
\end{tabular}

Out of 300 patients, 296 (98.67\%) presented with vaginal discharge while $40 \%$ patients had pain in lower abdomen, $20 \%$ patient with pruritus vulva, $18 \%$ patient with dyspareunia and $1.33 \%$ patients presented with foul smelling. On per vaginal examination out of 300 cases $249(83 \%)$ were normal, $10.33 \%$ cases presented with Normal uterus with tenderness in fornix and $6.67 \%$ cases presented with bulky uterus with tenderness in fornix. Tenderness were present in $17 \%$ cases. Whiff test was positive in $83(27.67 \%$ ) cases and negative in $217(72.33 \%)$ cases. Wet mount findings were normal in $147(49 \%)$ cases, hyphae and pseudohyphae were seen in $25 \%$ cases, Clue cells in $23 \%$ cases while flagellated protozoa were seen in $3 \%$ cases. Gram staining was normal in $217(72.3 \%)$ cases, pus cells, gram positive bacteria were seen in $14.7 \%$ cases. Pus cells, gram negative bacteria were seen in $15 \%$ cases. Overall gram positivity seen in 83 cases (27.66\%). Most of the cases $210(70 \%)$ were observed normal on vaginal swab culture. Candida species were present in $27 \%$ cases while Trichomoniasis were present in 3\% cases. On ELISA test, $\mathrm{HbsAg}$ was positive in $9(3 \%)$ cases, VDRL positive in $1.67 \%$ and HIV positive in $0.67 \%$ cases. 
Table 2: Etiological examination by laboratory tests

\begin{tabular}{ccc}
\hline Tests & No. of patients & Percentage (\%) \\
\hline Whiff test & 217 & $72.3 \%$ \\
Negative & 83 & $27.7 \%$ \\
Positive & & \\
Wet mount & 147 & $49 \%$ \\
Normal & 75 & $25 \%$ \\
Hyphae and Pseduoyphae & 69 & $23 \%$ \\
Clue cells & 09 & $3 \%$ \\
Flagellated trophozoan & & \\
Gram staining & 217 & $72.3 \%$ \\
Normal & 41 & $13.7 \%$ \\
Pus cells, gram positive bacteria & 42 & $14 \%$ \\
Pus cells, gram negative bacteria & & \\
Vaginal swab culture & 210 & $70 \%$ \\
Normal & 81 & $27 \%$ \\
Candida spp. & 09 & $3 \%$ \\
Trichomoniasis & & $3 \%$ \\
Serological tests & 09 & $1.7 \%$ \\
HBsAg & 05 & $0.7 \%$ \\
VDRL & 02 &
\end{tabular}

Out of 300 cases most commonly diagnosed syndromes were vaginal discharge syndrome (54\%) followed by lower abdominal pain syndrome (17.33\%). No cases of genital ulcers and genital warts were reported.

\begin{tabular}{ccc}
\multicolumn{3}{c}{ Table 3: Distribution of the cases according to Pap Smear } \\
\hline Pap smear & No. of cases & Percentage (\%) \\
\hline Normal & 186 & $62 \%$ \\
Inflammatory & 97 & $32.33 \%$ \\
Inflammatory, bacterial vaginosis & 6 & $2 \%$ \\
Inflammatory, candidiasis & 7 & $2.33 \%$ \\
Inflammatory, trichomoniasis & 2 & $0.67 \%$ \\
low grade squamous epithelial lesion (LSIL) & 2 & $0.67 \%$ \\
Total & 300 & $100 \%$ \\
\hline
\end{tabular}

Table 4 showed distribution of cases according to etiological diagnosis, out of 300 cases 147 (49\%) cases were normal, Bacterial vaginosis was diagnosed in $21 \%$ cases, candidiasis was observed in $20.3 \%, 6.67 \%$ cases had mixed infection and $3 \%$ were of trichomonas.

Table 4: Distribution of the cases according to Final (Etiological) Diagnosis

\begin{tabular}{ccc}
\hline Etiological Diagnosis & No. of cases & Percentage (\%) \\
\hline Normal & 147 & $49 \%$ \\
Bacterial & 63 & $21 \%$ \\
candidiasis & 61 & $20.3 \%$ \\
Mixed infection & 20 & $6.7 \%$ \\
Trichomonas & 9 & $3 \%$ \\
Total & 300 & $100 \%$ \\
\hline
\end{tabular}

\section{DISCUSSION}

Reproductive tract infections are most common gynecology complaint among women in reproductive age group. Vaginal discharge is often reported to be the most frequent RTI among women. ${ }^{5}$ In our study, out of the 300 women, 296 (98.7\%) presented with vaginal discharge. This is due to the fact that awareness related to RTIs and health seeking behavior is inadequate among them. Excessive vaginal discharge was reported, due to menstrual disorders and unhealthy cervix leading to cervical erosion and infections leading to abdominal pain. Abdominal pain can be explained by associated pelvic congestion. Also the presence of backache and pain abdomen indicates the presence of sub clinical involvement of surrounding tissues or irritation of paracervical nerves by chronic infections. Hawkes et al. ${ }^{6}$ in their study $94 \%$ women reported with abnormal vaginal discharge, Patnaik et al. ${ }^{7}$ concluded that vaginal discharge 
syndrome is the most commonly diagnosed syndromic diagnosis. Shethwala et al. ${ }^{8}$ showed that the most common symptom reported was vaginal discharge 147 (98\%), Bote et al. ${ }^{9}$ found in their study that major symptom reported was vaginal discharge. On per vaginal examination, in our study, out of 300 cases, $249(83 \%)$ were normal, $10.3 \%$ cases presented with normal size uterus and tenderness in fornix and $6.7 \%$ cases presented with bulky uterus and tenderness in fornix. Fornicial tenderness was present in cases $17 \%$. In women tenderness was most common with lower abdominal pain. This indicated that awareness of RTIs and health seeking behavior is inadequate in those women. Excessive vaginal discharge was because of erosion of cervix, pain in abdomen, back pain and menstrual disorders. Presence of back ache and pain in abdomen indicated the possibility of sub clinical involvement of surrounding tissues or irritation of paracervical nerves by chronic infections. Pain in abdomen can be explained by associated pelvic congestion and tenderness. Ray et al. ${ }^{1}$ in their study observed lower abdominal tenderness in $13.5 \%$ of women. Chauhan $\mathrm{V}$ et $a l .{ }^{10}$ in this study, cervical motion tenderness and nabothian follicles were observed in cases of cervicitis, bacterial vaginosis and trichomoniasis.

Out of 300 cases, whiff test was positive in 83 $(27.7 \%)$ cases. Whiff test confirmation of bacterial vaginosis if fishy smell present then whiff test positive. According to wet mount findings were normal in 147 (49\%) cases, Hyphae and pseudohyphae seen in $25 \%$ cases, Clue cells seen in $23 \%$ cases, while flagellated protozoa were seen in $3 \%$ cases. Wet mount is confirmation of bacterial vaginosis, candidiasis and trichomonas. In bacterial vaginosis clue cells are seen in wet mount and Hyphae and pseudohyphae are seen in candidiasis and flagellated protozoa are seen in trichomoniasis. Out of 300 cases, most of the cases 210 $(70 \%)$ were sterile on vaginal swab culture. candida species were present in $27 \%$ cases while Trichomoniasis were present in 3\% cases. Swab culture is confirmatory diagnosis of candida and trichomonas. Vasantha et al. ${ }^{11}$ in their study whiff test, wet mount and vaginal swab culture showed by laboratory diagnosis which was $52 \%$. In present study, out of 300 patients, gram staining was found normal in $211(70.3 \%)$ cases, pus cells, gram positive bacteria were seen in $14.7 \%$ cases. Pus cells, gram negative bacteria were seen in $15 \%$ cases. Gram staining is confirmatory diagnosis of bacterial vaginosis and diagnosis for gram positive and gram negative bacteria. Bohara et al. ${ }^{12}$ found in their study that thirteen percent had trichomoniasis and 7\% had gonorrhoea identified in Gram stained smears and cultures. Aggarwal et al. ${ }^{2}$ found that out of 234 Gram stained smears, $70(29.9 \%, 95 \% \mathrm{CI}=24.4$ $36.0 \%$ ) showed presence of $>5$ pus cells/OIF. On ELISA test, HbsAg was positive in $9(3 \%)$ cases, VDRL positive cases were in $1.7 \%$ and HIV positive were $0.67 \%$ cases. Aggarwal et al. ${ }^{2}$ only two women were HIV positive; one showed VDRL reactivity, though the VDRL titre was low (1:4), she was also reactive by TPHA test. On pap smear finding, out of 300 cases, $186(62 \%)$ cases were reported normal, $32.3 \%$ cases were inflammatory, $2 \%$ bacterial vaginosis, $2.33 \%$ candidiasis, $0.67 \%$ trichomoniasis and $0.67 \%$ were low grade squamous epithelial lesion (LSIL). Prabha et al. ${ }^{5}$ pap smear showed $32.9 \%$ inflammatory changes and $0.25 \%$ low grade squamous intraepithelial lesion. Garg et al. ${ }^{13}$ Pap smear showed $32.9 \%$ inflammatory changes and $0.25 \%$ low grade squamous intraepithelial lesion. Microbiologically, $33.14 \%$ were positive for at least one organism. On etiological diagnosis, out of 300 cases, 147 (49\%) cases were normal, bacterial vaginosis was diagnosed in $21 \%$ cases, candidiasis was observed in $20.3 \%$, $6.7 \%$ cases had mixed infection and $3 \%$ were of trichomonas. Endogenous infections are more prevalent (Bacterial vaginosis, candidiasis) followed by trichomoniasis. Most commonly bacterial vaginosis is diagnosed by laboratory test. Patnaik et $a l^{7}{ }^{7}$ The most commonly infections identified by laboratory diagnosis was bacterial vaginosis $(14.3 \%)$. Ray et al. ${ }^{1}$ found that laboratory diagnosis of patients most common etiology was candida albicans. In a study by Shethwala $\mathrm{et} \mathrm{al} .{ }^{8}$ out of 150 patients, 34 (22.6\%) had bacterial vaginosis, 27 (18\%) had candidiasis whereas, $24(16 \%)$ were found to have HSV-II. 4 (2.7\%) patients were having positive test for syphilis. In a study of Aggarwal et al. ${ }^{2}$ most common cause was bacterial vaginosis (positive $=21.4 \%, 95 \% \mathrm{CI}=16.6$ $27.1 \%$; intermediate score $=17.5 \%, 95 \% \mathrm{CI}=13.2-$ $22.9 \%)$, followed by candidiasis $(13.7 \%, 95 \% \mathrm{CI}=98-$ $18.7 \%)$ and trichomoniasis $(0.4 \%, 95 \% \mathrm{CI}=0-2.6 \%)$. No etiological diagnosis for vaginal discharge could be established in approximately half of the women. Only two women were HIV positive; one was reactive by VDRL and TPHA tests. Prabha et al. ${ }^{5}$ found prevalence of reproductive tract infections/sexually transmitted infections by laboratory diagnosis of $33.1 \%$. Most common infection diagnosed by laboratory test was bacterial vaginosis $(14.3 \%)$. In a study by Shah $\mathrm{M}$ et al. ${ }^{14}$ out of $183(78.54 \%)$ pregnant females had vaginal discharge on clinical examination and Candida albicans was the most common clinical diagnosis among them. Of 183 cases diagnosed clinically as vaginal discharge syndrome, $38(20.7 \%)$ were tested positive in laboratory investigations. Out of 50 clinically negative cases, $9(18 \%)$ were detected positive for one of the STIs on laboratory testing. 


\section{CONCLUSION}

The treatment may be initiated on the basis of signs and symptoms, however, it is essential that the treatment is modified as and when laboratory test results become available. The laboratory services need to be strengthened to ensure accurate and standardized availability of diagnostic services.

\section{REFERENCES}

1. Ray K, Muralidhar S, Bala M, Kumari M, Salhan S, Gupta SM, Bhattacharya M. Comparative study of syndromic and etiological diagnosis of reproductive tract infections/sexually transmitted infections in women in Delhi. International Journal of Infectious Diseases. 2009 Nov 30;13(6):e352-9.

2. Aggarwal P, Bhattar S, Sahani SK, Bhalla P. Utility of Laboratory Diagnosis for Confirmation of the Syndromic Case Management in Married Indian Women with Vaginal Discharge. International journal of health sciences. 2016 Oct;10(4):516.

3. World Health Organization. Prevention and control of sexually transmitted infections: draft global strategy: report by the Secretariat. In: Prevention and control of sexually transmitted infections: draft global strategy: report by the Secretariat 2006.

4. World Health Organization. Reproductive health strategy to accelerate progress towards the attainment of international development goals and targets. 2004, Geneva:14-19.

5. Prabha MLS, Sasikala G, Bala S. Comparison of syndromic diagnosis of reproductive tract infections with laboratory diagnosis among rural married women in Medak district, Andhra Pradesh. Indian J Sex Transm Dis. 2012;33(2):112-5.

6. Hawkes S, Morison L, Foster S, Gausia K, Chakraborty J, Weeling R, Mabey D. Reproductive-tract infections in women in low-income, low-prevalence situations: assessment of syndromic management in Matlab, Bangladesh. The Lancet. 1999 Nov 20;354(9192):177681.

7. Patnaik L, Sahu T, Sahani NC. Syndromic diagnosis of $\mathrm{RTI} / \mathrm{STI}$ among women of reproductive age group. Indian J Community Med 2008;4(1).

8. Shethwala N, Mulla S. Study on reproductive tract infection among the female patients attending the gynecology OPD in a teaching hospitals of Gujarat-India. Int J Med Sci Public Health 2014;3(1):123-125.

9. Bote MM, Bedre RC, Solanki HB, Shenoy AG, Suryawanshi SR. Syndromic Diagnosis vs. Laboratory Diagnosis of Reproductive Tract Infections among Married Women of Reproductive Age Group in Urban Slum of Mumbai. Community Med 2015;6(4):513-8.

10. Chauhan V, Shah M, Thakkar S, Patel SV, Marfatia Y. Sexually transmitted infections in women: A correlation of clinical and laboratory diagnosis in cases of vaginal discharge syndrome. Indian dermatology online journal. 2014 Nov;5(Suppl 1):S1.

11. Vasantha L, Leela S. Comparison of Laboratory Diagnosis and Syndromic Approach in the Management of Symptomatic Vaginal Discharge. International Journal of Science and Research (IJSR) 2013.

12. Bohara MS, Joshi AB, Lekhak B, Gurung G. Reproductive tract infections among women attending gynaecology outpatient department. International Journal of Infection and Microbiology. 2012 Oct 9;1(1):29-33.

13. Garg S, Bhalla P, Sharma N, Sahay R, Puri A, Saha R, Sodhani P, Murthy NS, Mehra M. Comparison of selfreported symptoms of gynaecological morbidity with clinical and laboratory diagnosis in a New Delhi slum. Asia Pacific Population Journal. 2001;16(2):75-92.

14. Shah M, Deshmukh S, Patel SV, Mehta K, Marfatia Y. Validation of vaginal discharge syndrome among pregnant women attending obstetrics clinic, in the tertiary hospital of Western India. Ind J Sex Transm Dis 2014 Jul;35(2):118.

\section{Source of Support: None Declared} Conflict of Interest: None Declared 